\title{
0 recrudescimento da teoria do capital humano
}

\author{
José dos Santos Souza ${ }^{1}$
}

O conjunto de transformações ocorridas no estágio atual do desenvolvimento do capital traz consigo o rejuvenescimento da Teoria do Capital Humano. Para compreendermos a forma como vem se dando esta nova ofensiva do capital no campo da teoria e das práticas educacionais, procuraremos pontuar seus elementos fundamentais, para posteriormente tratar das evidências de sua atualização no bojo do discurso neoliberal e nas práticas concretas da burguesia pós-fordista. Entretanto, não é nossa pretensão fazer aqui uma abordagem detalhada acerca da Teoria do Capital Humano, tampouco pretendemos ser inéditos em nossa crítica a esta teoria. Esta tarefa já foi suficientemente cumprida por diversos autores ${ }^{2}$.

A Teoria do Capital Humano tem suas bases teórico-metodológicas na economia neoclássica, pois parte do pressuposto de que o desenvolvimento das economias nacionais em estágios inferiores se dá pelo aumento necessário da desigualdade, em médio prazo, o que possibilita o aumento crescente das taxas de acumulação; e pela posterior redistribuição da riqueza, em longo prazo, que seria conseqüência natural

1. Doutor em Sociologia pela UNICAMP, professor de Política Educacional do Departamento de Filosofia e Ciências Humanas da UESB, onde coordena o Núcleo de Estudos e Pesquisas Sobre Trabalho, Política e Sociedade - NETPS.

2. Ver: Gaudêncio Frigotto. A Produtividade da Escola Produtiva: um (re)exame das relações entre educação e estrutura econômico-social e capitalista. 3ª Edição. São Paulo: Cortez: Autores Associados, 1989. 235 p.; Bruno Lautier e Ramon Tortajada. École, Force de Travail et Salariat: matériaux pour une critique de l'économie de l'éducation. Grenoble: Presses Universitaires de Grenoble, 1978. 205 p. 
do fortalecimento da economia. Nesta visão, na medida em que o crescimento atingido determinaria níveis mínimos de desemprego, a produtividade aumentaria e haveria uma crescente transferência dos níveis de baixa renda do setor tradicional para os setores modernos, produzindo salários mais elevados. Assim, o desenvolvimento social se consolidaria, naturalmente, em decorrência da prosperidade econômica alcançada ${ }^{3}$.

Essa vertente de interpretação dos investimentos em capital humano nasce da necessidade da economia neoclássica explicar satisfatoriamente o crescimento econômico do mundo ocidental nos períodos de estabilidade alcançada nas décadas que se seguem à II Grande Guerra Mundial. Os fatores input da função crescimento - capital e trabalho - não bastaram para explicar o output registrado - taxa de crescimento - nas décadas de 1950 e $1960^{4}$. Durante certo tempo prevaleceu a compreensão de que esse resíduo da taxa de crescimento era um "terceiro fator" que, para alguns, era a técnica, e para outros, era simplesmente uma incógnita que a própria economia ainda não conseguira decifrar. Dois autores se destacaram na busca do "desvendamento" desse mistério: Becker e Schultz $z^{5}$. Foram estes os teóricos que "deram à luz" as teorias sobre o capital humano que hoje servem de fundamento para as formulações e práticas na área educacional por parte de diversos governos e organizações da sociedade civil, na forma de investimento em recursos humanos - especialmente em formação/qualificação da força de trabalho. Vejamos o eixo central de argumentação desses teóricos. Para Shultz

Embora seja óbvio que as pessoas adquiram capacidades úteis e conhecimentos, não é óbvio que essas capacidades e esses conhecimentos sejam uma forma de capital, que esse capital seja, em parte substancial, um produto do investimento deliberado, que têm-se desenvolvido no seio das sociedades ocidentais a um índice muito mais rápido do que o capital convencional (não-humano), e que o seu crescimento pode muito bem ser a característica mais singular do

3. Frigotto, op. cit., p. 39.

4. Bárbara Freitag. Escola, Estado \& Sociedade. 6’ㅡ Edição. São Paulo: 1986. 142 p.

5. Gary S. Backer. Human Capital: theoretical and empirical analysis, with special Reference to Education. $3^{\text {a }}$ Edição. Chicago: The University of Chicago Press, 1993. 390 p.; Theodore W. Schultz. Investing In People: the economics of population quality. California: California University, 1981; Theodore W. Schultz. 0 Capital Humano: investimentos em educação e pesquisa. Tradução de Marco Aurélio de Moura Matos. Rio de Janeiro: Zahar, 1973.250p.

6. Schultz, op. cit., p. 31.

160 O recrudescimento da teoria do capital humano 
sistema econômico. Observou-se amplamente que os aumentos ocorridos na produção nacional têm sido amplamente comparados aos acréscimos de terra, de homenshora e de capital físico reproduzível. O investimento do capital humano talvez seja a explicação mais consentânea para esta assinalada diferença.

Nesta mesma linha de argumentação, embora numa perspectiva mais empiricista, Becker faz a seguinte observação:

Muito se sabe hoje, sobre os efeitos da educação nos salários, na ocupação, no emprego e desemprego de homens e mulheres de várias raças e grupos étnicos de muitos países. Também é muito conhecida a ligação entre taxas de natalidade e investimentos em educação e treinamento, bem como a influência das famílias no capital humano e no progresso econômico. ${ }^{7}$

A partir daí, Becker empreende estudos empíricos sobre o papel do investimento em educação. Sua indicação inicial é de que sua análise do capital humano está em parte incentivada por um desejo de avaliar as propostas para melhorar a qualidade da força de trabalho por meio da educação, do treinamento, da assistência médica e da assistência à criança. Mas afirma que seu principal propósito é, de fato, remover um pouco do mistério econômico e social do mundo em que vivemos ${ }^{8}$. Com base em uma vasta investigação empírica sobre o papel da educação e do treinamento na elevação salarial dos indivíduos, Becker compreende que:

As diferenças de salários entre pessoas, áreas, ou períodos de tempo normalmente são concebidas como o resultado de diferenças em capital físico, em potencial científico-tecnológico, em habilidades, ou de diferenças em tipos de instituições (como sindicatos ou cooperativas). A discussão

7. Trecho por nós traduzido para o português a partir do seguinte fragmento, na língua original: “Much is now know for many countries about the effects of education on earnings, occupation, employment, and unemployment of both men and women and various races and ethnic groups. Much too is known about the link between birth rates and investments in education and training, how families influence the human capital and economic progress" (Becker, op. cit., p. 25).

8. Se por um lado Backer desvenda o mistério que envolvia o papel econômico da educação, por outro, suas teorias sobre o retorno individual e social dos investimentos em capital humano ofuscam o significado deste capital no processo de valorização do capital. 
prévia indica, porém, que aquele investimento em capital humano também tem um efeito importante nos salários observados, pois os salários tendem a ser o líquido de custos de investimento e o total de lucros de investimento. Realmente, uma avaliação da importância direta e indireta de capital humano parece solucionar algumas confusões no que concerne a resultados empíricos sobre salários. ${ }^{9}$

Essa linha de interpretação, então, busca traduzir o montante de investimento que uma nação ou os indivíduos fazem em formação/qualificação profissional, na expectativa de retornos adicionais futuros traduzidos na forma de aumento salarial. O cerne desta teoria consiste na consideração de que o somatório imputado à produtividade do estoque de capital físico e estoque de trabalho da economia, ao longo de determinado tempo, corresponde apenas a uma parcela do crescimento econômico. Há um resíduo que não é explicado pelo acréscimo do estoque de capital e de trabalho. E a existência desse resíduo é explicada pelo investimento nos indivíduos, denominado analogicamente "capital humano", que engloba o investimento em educação formal, treinamento, saúde do trabalhador etc. Desse modo, a Teoria do Capital Humano pretende complementar os fatores explicativos do desenvolvimento econômico, segundo a concepção neoclássica, dando sua interpretação à alta de salários do fator trabalho nos países mais desenvolvidos na época de ouro do capitalismo e explicando, no nível individual, os diferenciais de renda ${ }^{10}$.

Como se percebe, de acordo com os teóricos do capital humano, a formação ou qualificação da força de trabalho constitui um dos fatores fundamentais para explicar economicamente as diferenças de capacidade de trabalho e, conseqüentemente, as diferenças de produtividade e renda. Se do ponto de vista macroeconômico, o investimento no "fator humano" passa a significar um dos determinantes básicos para aumento da produtividade e elemento de superação do atraso econômico, do ponto

9. Trecho por nós traduzido para o português a partir do seguinte fragmento, na língua original: “Differences in earnings among persons, areas, or time periods are usually said to result from differences in physical capital, technological knowledge, ability, or institutions (such as unionization or socialized production). The previous discussion indicates, however, that investment in human capital also has an important effect on observed earnings because earnings tend to be net of investment costs and gross of investment returns. Indeed, an appreciation of the direct and indirect importance of human capital appears to resolve many otherwise puzzling empirical findings about earnings" (backer, op. cit., p. 95).

10. Frigotto, op. cit., p. 39 e 40.

\begin{tabular}{l|l}
\hline 62 & 0 recrudescimento da teoria do capital humano
\end{tabular} 
de vista microeconômico, tal investimento constitui o fator explicativo das diferenças individuais de produtividade e de renda e, conseqüentemente, de mobilidade social:

O suposto básico microeconômico é de que o indivíduo, do ponto de vista da produção, é uma combinação de trabalho físico e educação ou treinamento. Supõe-se, de outra parte, que o indivíduo é produtor de suas próprias capacidades de produção, chamando-se então, de investimento humano o fluxo de despesas que ele deve efetuar, ou que o Estado efetua por ele, em educação (treinamento) para aumentar a sua produtividade. A um acréscimo marginal de escolaridade, corresponderia um acréscimo marginal de produtividade. A renda é tida como função da produtividade, donde, a uma dada produtividade marginal, corresponde uma renda marginal. Na base deste raciocínio (silogístico) infere-se literalmente que a educação é um eficiente instrumento de distribuição de renda e equalização social. O cálculo da rentabilidade é efetivado a partir das diferenças entre a renda provável de pessoas que não freqüentaram a escola e outras, semelhantes em tudo o mais [...] e que se educaram. Daí decorrem também as teses relacionadas com a mobilidade social. ${ }^{11}$

Esta linha de raciocínio compreende que a educação é criadora de capacidade de trabalho; que o investimento marginal no campo da formação/qualificação da força de trabalho permite uma produtividade marginal; e que o indivíduo, produzindo mais, conseqüentemente ganhará mais. A Teoria do Capital Humano concebe as relações de produção capitalistas como justas e regidas pela lei da oferta e da procura e o salário ou a renda como preço do trabalho, de modo que, de acordo com este raciocínio, a definição da renda é uma decisão individual. Não se considera o fato de a sociedade capitalista ser composta por uma parcela restrita de proprietários de meios de produção e por um grande contingente de indivíduos que não dispõem de capital físico para produzir. Na visão dos teóricos do capital humano, uma vez que o indivíduo ou o Estado investe em formação/qualificação, o resultado é o aumento das rendas individuais, de acordo com seu mérito pessoal, e em médio ou longo prazo, este investimento lhe permitirá ter acesso ao capital físico ou dispor do mesmo status e privilégios dos que o possui12.

11. Idem, ibidem, p. 44.

12. Idem, ibidem, p. 50.

Marxismo e educação

cadernos cemarx, n-3-2006 163 
$\mathrm{Na}$ ótica do capital humano, enquanto a educação é tida como fator básico de mobilidade social e geração de renda individual, ou como fator de desenvolvimento econômico, o próprio "fator econômico" é posto como sendo o maior responsável pelo acesso e permanência na trajetória escolar e pelo rendimento ao longo desta trajetória, transformando o elemento determinante em determinado ${ }^{13}$. Esse caráter circular da Teoria do Capital Humano é uma derivação da concepção de homem e de sociedade que ela busca veicular e legitimar, bem como da função de escamoteamento das relações de produção que ocorrem concretamente na sociedade capitalista. A questão fundamental que se coloca é que o método em que esta teoria se fundamenta para analisar o fenômeno social concreto traduz e, ao mesmo tempo, constitui-se em apologia da concepção burguesa de homem, de sociedade e de relações de produção e reprodução social da vida material ${ }^{14}$.

Não obstante, é exatamente esse caráter circular da Teoria do Capital Humano o que denuncia, nesse caso, as formas como a objetividade e a racionalidade constituem-se em jargões básicos do discurso burguês no campo educacional. A aura de objetividade e de racionalidade que caracteriza este tipo de análise, mais que o pretenso status de cientificidade, busca se fazer entender como isenta e neutra, como se isto fosse possível no trabalho científico, como se o sujeito cognoscente tivesse esta capacidade de isenção. A esse respeito, a crítica de Frigotto ${ }^{15}$ é implacável, quando afirma que os teóricos do capital humano se baseiam no argumento da neutralidade de seu método de análise para passar a idéia de que a ordem do capital, suas leis e suas relações de produção obedecem uma lógica e uma ordem natural.

Sob o conceito de homem genérico, abstrato e "livre", a Teoria do Capital Humano evidencia seus vínculos com o arcabouço da teoria econômica neoclássica, especialmente na forma como os princípios do liberalismo individual constituem o fio condutor de sua análise. Do mesmo modo, evidencia também como essa análise está permeada pela idéia de que, em um mercado em concorrência perfeita, o ótimo de cada um, racionalmente calculado em longo prazo, constitui para o ótimo de longo prazo de todos ${ }^{16}$.

13. Idem, ibidem, p. 51.

14. Idem, ibidem, p. 52.

15. Idem, ibidem, p. 57.

16. Idem, ibidem, p. 59. 
Outro aspecto refere-se à separação estanque do econômico, do político e do social presente na linha de análise da Teoria do Capital Humano. Isto faz parecer que existe uma autonomia supra-histórica entre a posição econômica, a posição social e a distribuição de poder na sociedade.

Este viés de análise que separa as dimensões econômicas e de poder e que coloca, de outra parte, a determinação de um "fator" ou de outro, como dependente do estágio de desenvolvimento capitalista, faz com que as análises passem a postular a superação do conflito de classe sem uma mudança do modo de produção capitalista. Esta é tipicamente a visão neocapitalista. ${ }^{17}$

Assim, o conceito de capital se reduz a um mero fator de produção onde as máquinas em si, como capital constante e técnico, são tidas como capazes de criar valor independentemente da intervenção do trabalho humano - trabalho vivo. Por outro lado, ocorre uma espécie de nivelamento entre capital constante e capital variável na produção do valor, de modo que o trabalhador assalariado é visto não apenas como "proprietário" de força de trabalho, mas também como proprietário de um capital - o capital humano. O salário recebido, então, passa a ser considerado não como preço dessa força de trabalho, mas como uma remuneração do capital humano adiantado pelo trabalhador. Por meio do fetiche da maquinaria e da mercadoria "capital humano", essa ordem de pensamento mascara a origem real e única da produção da mais-valia: a apropriação privada do trabalho humano excedente. Em vez de centrar a análise no valor-trabalho e nas relações de classe, a análise passa a centrar-se em uma relação de troca de agentes de produção concebidos igualmente livres ${ }^{18}$.

O conteúdo ideológico que está por detrás dessa teoria é a idéia de que, no mundo da produção, todos os homens são "livres" para ascenderem socialmente e esta ascensão depende única e exclusivamente do mérito individual e/ou da administração racional dos seus recursos. Essa idéia se expressa no âmbito escolar na forma de uma compreensão de que a não aprendizagem, a evasão, a repetência são problemas individuais, conseqüência da falta de esforço, da "não-aptidão", da falta de vocação dos indivíduos. Enfim, Teoria do Capital Humano assume, no âmbito político, a forma de 
justificativa das desigualdades entre as classes, por aspectos individuais, mascarando as formas de extração da mais-valia; especificamente no âmbito educacional, de forma semelhante, "mascara a gênese da desigualdade no acesso, no percurso e na qualidade de educação que têm as classes sociais"19.

Não obstante, durante os períodos de prosperidade do capital no pós-guerra, a Teoria do Capital Humano ofereceu o embasamento teórico para o planejamento educacional de diversos países. Também funcionou como um mecanismo de conformação do conflito de classe no campo educacional, na medida em que deu corpo à ideologia de que a formação/qualificação da força de trabalho é um direito e dever de todos e o Estado tem a obrigação de criar as condições para que todos tenham acesso à educação. Isto reforçava o argumento de que caberia ao Estado a autoria dos investimentos e do planejamento educacional.

Por trás dessa ideologia do Estado bem-feitor sustentada pelos teóricos do capital humano, estava a argumentação pseudocientífica de que o investimento em educação é feito em nome do desenvolvimento da nação e este produz uma taxa de crescimento que beneficia a todos. Com base no pressuposto de uma sociedade harmoniosa e capaz de superar seus conflitos internos, essa ordem de interpretação da economia educacional sugere a existência de uma taxa de retorno social e individual para os investimentos em educação. Segundo Freitag ${ }^{20}$,

Isto significa em outros termos que a taxa de lucro criada com maior produtividade dos indivíduos devida ao seu mais em educação é repartida de maneira justa entre o indivíduo e o Estado. Aquele porque investiu em esforço, energia e tempo, perdendo potencialmente salários se tivesse utilizado esse tempo para seguir um trabalho remunerado. O Estado receberia de volta, sob forma de taxas e impostos, os investimentos originais mais a parcela da taxa de lucro, justamente repartida entre ele e o indivíduo.

Não se levava em consideração neste argumento que quem mais lucra com tais investimentos são as empresas privadas. Na realidade, o que havia era uma socialização dos gastos educacionais, mediada pelo Estado, para atender aos interesses do

19. Idem, ibidem, p. 67.

20. Freitag, op. cit., p. 28.

$16 \overline{66}$ O recrudescimento da teoria do capital humano 
empresariado e do capital monopolista. Decerto, esses investimentos em formação/ qualificação da força de trabalho, no contexto do processo de valorização do capital, não se materializam para atender os interesses da classe trabalhadora, no sentido de melhorar sua qualidade de vida, como potencial emancipador, mas sim para tornar ainda mais eficazes as relações de dominação. Vistos no contexto da reprodução ampliada, os investimentos em educação devem ser concebidos como investimento em capital variável para otimizar os investimentos em capital constante e, desse modo, garantir o aumento da produtividade. Justamente por esta razão, esses investimentos funcionavam como um eficiente mecanismo de conformação do conflito de classe no campo da política educacional do Estado benfeitor ${ }^{21}$.

Ademais, segundo o modelo da economia e do planejamento educacional baseado na Teoria do Capital Humano, o papel da economia da educação é ajustar, por meio de uma determinada política de investimentos, o nível de qualificação da força de trabalho para atender adequadamente às demandas produtivas, sempre condicionadas aos ciclos e às crises geradas pela economia capitalista. Desse modo, cria-se...

[...] uma certa flexibilidade do sistema capitalista face a tais crises. Sob a ideologia do desenvolvimento e do crescimento continuado da economia e alegando ao mesmo tempo assegurar empregos duradouros à força de trabalho disponível, defendem, em verdade, os interesses da maximização dos lucros da empresa privada, pois mantêm em reserva um potencial de trabalhadores que constantemente são reciclados em função das novas demandas geradas pela dinâmica e irracionalidade do modo de produção. O planejamento educacional constitui assim uma maneira de manipular "o exército industrial de reserva", dando-lhes sua plena funcionalidade: fornecer a cada momento a força de trabalho necessária à expansão ou contenção da produção e degradar os salários. ${ }^{22}$

Em suma, o modelo da economia educacional propalado pelos teóricos do capital humano ofusca a essência do problema: o aumento da mais-valia relativa, obtida por intermédio da maior qualificação da força de trabalho. Em outras palavras, esse mo-

21. Idem, ibidem, p. 28.

22. Idem, ibidem, p. 30.

Marxismo e educação

cadernos cemarx, n-3-2006 167 
delo interpretativo mantém-se na superficialidade do problema; não reconhece e/ou procura escamotear o fato de que a maximização da taxa de retorno individual dos investimentos educacionais corresponde à maximização dos lucros ambicionada pelos capitalistas, de modo que "a taxa de retorno social e individual" corresponde exatamente à taxa de lucro das empresas empregadoras. Assim, para assegurar o processo de acumulação do capital, conforme a teoria do valor de Marx, ocorre o seguinte:

Os indivíduos ou o Estado, investindo pois na qualificação da força de trabalho, e justamente para aqueles setores e ramos em que há necessidade de trabalhadores mais ou menos qualificados, criam um valor. Este, no ato da troca, recebe seu equivalente (tempo socialmente necessário para produzi-lo) em salário. Mas na hora que essa força de trabalho é empregada no processo produtivo, ela gera mais valor do que o salário percebido. Este excedente não retorna ao indivíduo ou ao Estado que nele investiram para qualificá-lo, mas é apropriado pelo comprador, o empresário capitalista. ${ }^{23}$

Ao abordar as mudanças recentes na compreensão da função econômica atribuída à escola, Gentili ${ }^{24}$ estabelece relações entre as mudanças profundas ocorridas na sociabilidade do capital e a crise do capitalismo contemporâneo. O argumento central de sua análise é de que a mudança atribuída à função econômica da escola radica-se no estrondoso desmoronamento, a partir dos anos 1970, da "era de ouro" do capitalismo. Para Gentili, a promessa da escola como entidade integradora determinou a expansão dos sistemas escolares nacionais a partir do final do século XIX, quando estes eram considerados pelos grupos dominantes e pelas massas que lutavam por sua democratização como um poderoso dispositivo institucional de integração social em um sentido amplo. Mas "a crise dos anos 1980 marcara o início de uma profunda desarticulação dessa promessa integradora em todos os seus sentidos" 25 . Tal ruptura se torna mais definida justamente quando o papel econômico da educação é revalorizado - a partir dos anos 1980, no caso brasileiro - e proliferam-se discursos enfáticos

23. Idem, ibidem, p. 31-32.

24. Pablo Gentili. Educar para o desemprego: a desintegração da promessa integradora. In: Gaudêncio Frigotto (Org.). Educação e Crise do Trabalho: perspectivas de final de século. Petrópolis: Vozes, 1998. p.76-99. 25. Idem, ibidem, p. 79. 
acerca da importância produtiva dos conhecimentos e de crescente reformulação do papel da escola no sentido de garantir a competitividade das economias na era da globalização. Gentili destaca que:

[...] a desintegração da promessa integradora não tem suposto a negação da contribuição econômica da escolaridade, e sim uma transformação substantiva em seu sentido. Passou-se de uma lógica da integração em função de necessidades e demandas de caráter coletivo [...], a uma lógica econômica estritamente privada e guiada pela ênfase nas capacidades e competências que cada pessoa deve adquirir no mercado educacional para atingir uma melhor posição no mercado de trabalho. ${ }^{26}$

Nesta mesma linha de análise, Frigotto ${ }^{27}$ percebe que as mudanças recentes no processo de trabalho e produção se expressam na superestrutura como uma alternativa teórica, econômica, ideológica, ético-política e educacional para a garantia das condições de acumulação do capital. Em outras palavras, a recomposição do capital tem se dado através da reedição das teses neoliberais de que o setor público é o responsável pela crise e que o mercado é a alternativa para a retomada das taxas de lucro, como se fosse o mercado o fim último da história. A partir daí, advém a tese do Estado mínimo e da necessidade de zerar todas as conquistas sociais, onde a lógica das leis do mercado passam a regulamentar as relações de produção - base teórica da recomposição do capital.

No campo educacional, o mercado constitui-se no sujeito educador de onde resulta uma filosofia utilitarista, imediatista, e uma concepção fragmentada do conhecimento, este concebido como mercadoria, em vez de processo em construção permanente. É óbvio que essa mudança substancial na valorização do poder regulador do mercado, em detrimento da valorização do Estado como principal agente regulador no campo educacional, vai demandar alguns ajustes na velha Teoria do Capital Humano. Em sua forma original, como já afirmamos, esta teoria conferia ao Estado o papel de principal

26. Idem, ibidem, p. 81.

27. Gaudêncio Frigotto. Os delírios da razão: crise do capital e metamorfose conceitual no campo educacional. In: P. Gentili (Org.). Pedagogia da Exclusão: crítica ao neoliberalismo em educação. Petrópolis: Vozes, 1995. Pág. 77-108.

Marxismo e educação

cadernos cemarx, n-3-2006 169 
investidor e planejador dos investimentos em capital humano, feito em nome do desenvolvimento dos Estados nacionais. Na atualidade, vivenciamos o recrudescimento da Teoria do Capital Humano sem o Estado como principal investidor, mas permeada pelo reforço e incentivo às iniciativas individuais, radicada na idéia do empreendedorismo como diferencial na acumulação de capital humano. Se algum papel resta ao Estado, este seria o de flexibilizar o sistema educacional para que as leis do mercado o regulem, de acordo com as demandas do setor produtivo. Para tal mudança, na avaliação de Frigotto, o pós-modernismo tem contribuído bastante:

À perspectiva fragmentária do mercado,[...] particularmente no campo educacional, junta-se o estilhaçamento dos processos educativos e de conhecimento veiculados pelas posturas pós modernistas que reificam a particularidade, o subjetivismo, o local, o dialeto, o capilar, o fortuito, o acaso. Nega-se não só a força do estrutural, mas a possibilidade de espaços de construção de universalidade, no conhecimento, na cultura, na política, etc. [...] O resultado da atomização do mercado e das perspectivas pós-modernistas, no plano político prático, não poderia ser mais perverso. Sob os conceitos de autonomia, descentralização, flexibilidade, individualização, pluralidade, poder local, efetiva-se uma brutal fragmentação do sistema educacional e do processo de conhecimento. ${ }^{28}$

Para Frigotto, assim como as teorias de desenvolvimento/ modernização nortearam os esforços de recomposição do capital para recuperar suas bases de acumulação a partir dos anos 1930, as teses pós-modernas da "Sociedade do Conhecimento" e da "Qualidade Total" têm norteado os esforços atuais de recomposição do capital na crise do regime de acumulação taylorista/fordista a partir dos anos 1970. As teses da qualidade total, formação flexível e polivalente e a tese da "sociedade do conhecimento" são apenas expressões de uma nova materialidade da crise e contradição do capitalismo no estágio atual de seu desenvolvimento e, portanto, denotam a continuidade da subordinação da educação à lógica da exclusão. Para tal compreensão, é didaticamente importante apreendermos que o modelo de investimento em capital humano está posto no contexto atual de forma renovada. Enfatizam-se, agora, as responsabilidades do indivíduo e da sociedade civil para com os investimentos nesse campo, diminuindo-se, assim, as responsabilidades estatais.

28. Idem, ibidem, p. 86 e 87.

170 O recrudescimento da teoria do capital humano 
Na nova materialidade da produção e reprodução social da vida material, onde a tese da "sociedade do conhecimento" emerge e com ela novos conceitos operacionais de qualidade total, flexibilidade, trabalho participativo em equipe, formação flexível, abstrata e polivalente etc, todo esse aparato conceitual tem como objetivo ofuscar os reais interesses do capital. Trata-se, na realidade, de um projeto de conformação psicofísica do trabalhador/cidadão às novas exigências do processo de trabalho e de produção.

A construção dessa nova materialidade e de seus mecanismos de mediação política desenvolvem-se "conjuntamente com um verdadeiro revolucionamento da base técnica do processo produtivo, resultado, em grande parte, do financiamento direto ao capital privado e indireto, pelo fundo público, na reprodução da força de trabalho"29. Obviamente, esse processo promove um grande impacto sobre o conteúdo, a divisão, a quantidade e a qualificação do trabalho. Ao mesmo tempo em que se demanda uma elevada qualificação e capacidade de abstração para o grupo de trabalhadores estáveis, para a grande massa de trabalhadores a questão da qualificação não se coloca como problema para o mercado. É nesse contexto que se dá a metamorfose conceitual chamada por Frigotto de "delírios da razão"30.

Portanto, os novos conceitos relacionados ao processo produtivo, à organização do trabalho e à qualificação do trabalhador têm uma estreita relação com a recomposição do capital diante da atual crise de acumulação. A integração, a qualidade e flexibilidade, os conhecimentos gerais e a capacidade de abstração rápida constituem-se nos elementos-chave para os saltos de produtividade e competitividade tão almejados pelo capital, em um contexto de crise acirrada de competitividade intercapitalista e de obstáculos sociais e políticos às tradicionais formas de organização da produção $0^{31}$. É exatamente nesse ponto que reside a atualidade da Teoria do Capital Humano.

Talvez por essa razão, Amaral $^{32}$ aponte corretamente que a necessidade de acompanhar a dinâmica de acumulação de capital requerida pela atual conjuntura tem encontrado na relação educação/trabalho o campo fértil para a implementação de estratégias de mudanças no campo da gestão de recursos humanos para a produção.

29. Idem, ibidem, p. 96.

30. Idem, ibidem, p. 97.

31. Idem, ibidem, p. 98.

32. Ângela Santana Amaral. Qualificação, Sociedade Civil e Desidentidade de Classe: os desafios para o sindicalismo.

In: Outubro - Revista do Instituto de Estudos Marxistas, São Paulo, №05, p. 29-45, 2001. 
Por um lado, o capital investe ostensivamente na área da qualificação e, de outro, os trabalhadores sustentam a luta histórica pela universalização da escola pública, laica e de qualidade.

Carente de uma leitura crítica mais radicalmente fundada no materialismo histórico-dialético, algumas interpretações pseudo-marxistas também vêem na formação/qualificação da força de trabalho a possibilidade de combate ao desemprego e geração de renda. Entendem a formação/qualificação como fator de desenvolvimento da produtividade e da qualidade da produção e, conseqüentemente, de crescimento econômico. Neste aspecto, identifica-se com a concepção burguesa, na medida em que atribui ao progresso técnico decorrente de maior qualificação da força de trabalho uma aparente neutralidade e sugere que o crescimento por ele gerado é igualmente benéfico tanto para a classe trabalhadora como para o empresariado. Ofusca-se, assim, as determinações dos antagonismos classistas, onde o progresso técnico é tido como neutro e autônomo.

172 O recrudescimento da teoria do capital humano 